\title{
New Words and Language Teaching
}

\author{
Xianfeng Zhou \\ School of Literature and Communication, Luoyang Normal University, Luoyang, 471022, China
}

\author{
Keywords: New words. Chinese teaching. Specification
}

\begin{abstract}
The emergence of new words is a linguistic phenomenon that can not be ignored in life.Chinese teachers should pay attention to the influence of new words in Chinese teaching and recept it Critically; Uphold the principle of "ism" , improve the cognition of new words :Judging the pragmatic features of new words and expressions,enable students to understand the right and wrong, beauty and ugliness, high under division of new words ;To carry out the overall evaluation of the type of new words and expressions, to enable students to adapt to the specific context level, select the new words with different types, to guide the students to live and study in the accurate and reasonable use of new words and expressions.
\end{abstract}

\section{Chinese teaching should pay more attention to the new words and expressions}

With the rapid development of the society, the intercourse between China and foreign countries has become more and more frequent and technology continues to evolve rapidly all of them has a great influence on the emergence of new words.In daily teaching, as long as a little attention it is easy to find that many new words were been used vividly in students' daily life , classroom and composition.Especially since 2003, new words are incorporated into the scope of test ,gradually caused widespread concern in society. [1]New words have become the new phenomena,and new problems in Chinese teaching which can not be ignored.If Chinese teachers can't make a proper guidance to the new words, it will affect the quality and efficiency of Chinese teaching.

For a long time,it always exit a different view in the academic circle as What kind of words are the new words.Wang Tiekun pointed out that new words is a new creation or from other languages, and new words also emergence from the nation's dialect words, or borrowed from archaisms and industry word, also refers to a new meaning, new usage inherent word. [2]Zhang Bin pointed out:that to analyze carefully, there are different levels of the ' new 'of new words. Some new, some are half of the new, some are refurbished.New also includes two categories: one category is introduced from outside,some of which are authentic imported goods, others with our own packaging;another kind is created by ourselves.Half of the new is means that the news words exit in the dialect and not in mandarin .

\section{The attitude of Chinese teachers for new words}

In today's society, Primary and middle school students get in touch with though network, television, books and other mass media,If the teacher pay no heed to these new words,show no interest in new words;if things continue this way it will produce estrangement between teachers and students ,and it is also not good for communication.As a Chinese teacher, treat the new words and expressions friendly, adopt a positive attitude,to accept the new word which meet standard in time, do not meet the new word standard to guide.

The language teacher should uphold the principle of "ism" attitude, improve the cognition of new words.New Chinese vocabulary has increased dramatically, more than one thousand annual .In the new revision of the "modern Chinese Dictionary" (Fifth Edition) increased new six thousand new vocabulary .As a Chinese teacher, not only had eyes for textbooks and classroom, 不but also look at the society, keep pace with the times, absorb new knowledge of Chinese from daily life, screening language from the real world , improve the new cognitive of vocabulary. What is the standardization of modern Chinese language, which is differ from modern Chinese standard, or even completely 
counter to the laws of language.in general,some new words are relatively easy to take root in the Chinese language system which can not find suitable words to replace, become a part of the Chinese vocabulary, it is consistent with the laws of language development.Sometimes new words can be replaced by Chinese vocabulary, especially some new words are translated by English word, while in Chinese, and the corresponding expression, this kind of words is the language of the burden, increasing the difficulty of the expression and understanding, do not follow the rules of language .For example, the "trouble" is said to "chabao" (trouble).However, if the code switching has added new semantic features, and new words are likely to become a new way of expression, such as "shopping",English as shopping, now a lot of fashion magazines and newspapers with the "shopping" a word, although conflicting with original semantic of Chinese, but inspire people to fling caution to the winds crazy purchase psychology, to incite-effect of business advertising, which is likely to become the new words in Chinese.so as an Chinese teacher we must have a comprehensive understanding of new words to express the effect from generating ,can not shut the door on new words.If you ignore the new words, does not take the initiative in cognition, can only be put off yourself and live apart, not only hindered the further development of knowledge, but also hinder the normal communication between teachers and students.

\section{Measures adopting in Chinese teaching}

As a Chinese teacher,we have a responsibility to collection new words in daily life, analyzing and classifying them.get ready for communicating with students and guide students to apply mew words in a right way.

\section{Help students identify and judge on the new words of life}

First of all,evaluate the pragmatic color of new words.New word itself have a certain color which pass on the understanding and evaluating of the specific phenomenon.Some new words with positive meanings is the civilized language,In contrast,some new words have a negative meanings,and destroy the health and pure of Chinese.Because of Primary and middle school students have a limitation in their knowledge and ability,can not make the correct value judgment of the new words ,and can not haen a dialectical view of beauty and ugliness, right and wrong, elegance and vulgarity in multi angle, multi-level, Chinese teachers should use their own advantages to help the students, so that they finally understand the pros and cons of new words.For example, students often use "cool", "awesome" and so on, even in the class and in the classroom. In view of this situation, teachers can't scold, on the country teachers must recognize the reality, and then communicating with students by using new words, to help them understand its essence, guide them in a necessary way.Chinese teachers should take a tolerant attitude, it will build a bridge in the feelings of teachers and students, so that the psychological distance between teachers and students will be more closer.Through this way,students will have an high interesting in learning Chinese,the efficiency of Chinese teaching and the teaching quality will improve too.

Second, evaluating different types of new words and expressions.From the external form, new words are divided into three kinds, one kind is digital, one kind is the letter type, there is a category of Chinese characters type.In the Chinese language system, written in formal new words, digital type does not conform to the rules of language development, it is similar to a language game,only suitable for network, mobile phone and other special occasions, so it can be concluded that there is no vitality, teachers should pointed out that as far as possible, use less or no.In recent years alphabet of new words has been large-scale appear, teachers should absorb them selectively .Alphabet of new words have various types, such as abbreviation type and non-abbreviation type,and there are also English abbreviations and Chinese abbreviations.The third category is Chinese characters, this kind of composition is the most complicated, it is difficult to judge from the external form, when in use should be based on this kind of new words circulation and the use of language environment to determine. About this question, we will also detail. 


\section{Guide students to live and study in the accurate and reasonable use of new words and expressions}

Using new words must conform to the standard, with the use of the environment(context) has the very big relations.A word in different language environment have different means.For example, in the Internet chat input "88", we all understand "goodbye"means; if it is transplanted to the real life,It will be said that he is a"fans"of a singer In colloquial situations, if in writing articles, it changed to "worship". [4]So it is necessary to limited using of new words in different contextual level .the highest level of Context is formal composition and examination,using new words as far as possible,such as standardized new words, some new words with stable semantics, Recognized by the society or appear in the dictionary; In the middle of Context level are written communication between general message or classmates and oral communication,some new words can be used in a social group so that the speaker can get the same sense of group identity, this kind of new words not only have the function of expression, also has the contact and to maintain the emotional effect; On the lowest rank of context is is network, mobile phone, personal diaries and other specific media and privacy of the environment,all of them have a same point that is more freedom and personalized,many types of new words can be used even though digital words. Therefore, the use of new words should be restricted to different context level,as long as consistent with the context level, the use of new words is the norm.

\section{Conclusion}

As a Chinese teacher, should pay more attention to the influence of new words to the language teaching, to strengthen the cognition, understanding, treat the new words kindly and critical reception.Uphold the principle of "ism" attitude, improve the cognition of new norms ,try to . Orient students towards a right way in using new words.Evaluating the pragmatic features of new words and expressions, enable students to understand the right and wrong, beauty and ugliness, high and under of new words.carry out the overall evaluation of the new words and expressions form type, to enable students to adapt to the specific context level, select the different types of new words so as to guide the students to live and study in the rational using of new words.

\section{References}

[1] Qi Dinghong: Coping strategies new words phenomenon, Hunan education,2008 fourth.

[2] Wang Tiekun: Research" Chinese new words in 10 years, Chinese Construction, 1991 fourth.

[3] Zhang Bin: Neologism dictionary preface, Xi'an, future publishing house, 2000 March.

[4] Jiang Meirong: The teacher should treat new words kindly, Guangxi Education",2006 third.

[5] The Ministry of education of the people's Republic of China: Chinese course standard of full-time compulsory education, Beijing, Beijing Normal University press, 2001 edition. 